\title{
Condicionantes Socioeconômicos e Ambientais dos Clubes de Convergência da Renda na Amazônia Legal 1985 a 2007
}

\author{
Gerson Medeiros da Silva - José Nilo de Oliveira Junior - Marcelo Bentes Diniz
}

Submetido: 26 de fevereiro de 2010; aceito para publicação: 07 de agosto de 2011

Resumo: Este trabalho analisa a formação de clubes de convergência na Amazônia legal no período de 1985 a 2007, condicionados por variáveis socioeconômicas, institucionais e ambientais. O caráter inovador deste trabalho está em testar pela primeira vez a importância do desmatamento como condicionante ambiental da formação dos clubes de convergência na Amazônia. Foi utilizada uma metodologia não paramétrica através da estimação de densidades de núcleo, matriz de transição e estimação de núcleos estocásticos para testar as evidências de convergência entre os municípios. Os resultados confirmaram a hipótese de convergência, grande dinâmica intrasseccional da renda e a formação de três clubes de convergência entre os municípios da Amazônia legal. O capital humano aparece como importante condicionante e o rebanho bovino e área de pecuária tem fraca significância no condicionamento da renda relativa municipal. O desmatamento e as variáveis institucionais não se mostraram significantes para o crescimento econômico dos municípios da Amazônia legal.

Os autores agradecem o apoio financeiro do Conselho Nacional de Desenvolvimento Científico e Tecnológico (CNPq) e da Fundação de Amparo à Pesquisa do Estado de Minas Gerais (FAPEMIG) e da Universidade Federal de Juiz de Fora para a elaboração deste artigo.

Gerson Medeiros da Silva

Mestre em Economia /PPGEconomia/UFPA - Endereço para contato: Av. Conselheiro Furtado, n. 1597 - CEP: 66.040-100 - Belem/ PA - Vínculo Institucional Governo do Estado do Pará E-mail: msggerson@yahoo.com.br

José Nilo de Oliveira Junior

Doutor em Economia /CAEN/UFC - Endereço para contato: Rua Augusto Corrêa, 01, Setor Profissional ICASA, $2^{\circ}$ andar - Guamá - CEP: 66.075-110 - Belem/ PA - Vínculo Institucional Programa de Pós-Graduação em Economia da Universidade Federal do Pará -PPGEconomia/UFPA E-mail: josenilo@ufpa.br, joseniloojr@yahoo.com.br

Marcelo Bentes Diniz

Doutor em Economia /CAEN/UFC - Endereço para contato: Rua Augusto Corrêa, 01, Setor Profissional ICASA, 2 andar - Guamá - CEP: 66.075-110 - Belem/ PA - Vínculo Institucional Programa de Pós-Graduação em Economia da Universidade Federal do Pará -PPGEconomia/UFPA E-mail: mbdiniz2007@hotmail.com 
Palavras-Chave: condicionantes ambientais, clubes de convergência, Amazônia legal, núcleos estocásticos

Classificação JEL: O47, R1 1

\begin{abstract}
This paper analyzes the formation of convergence clubs in Amazonia in the period 1985 to 2007 conditional on socio-economic, institutional and environmental. The innovative nature of this work is to test the first time the importance of deforestation and environmental condition of the formation of convergence clubs in the Amazon. A methodology through the nonparametric estimation of kernel densities, the transition matrix and estimation of stochastic kernels to test the evidence of convergence between the municipalities. The results confirmed the hypothesis of convergence, large intra-sectional dynamics of income and the formation of three convergence clubs among the municipalities of legal Amazonia. Human capital appears as a major constraint and the cattle and livestock area has low significance in determining the rent for municipal. Deforestation and institutional variables were not significant for economic growth municipalities of Amazonia.
\end{abstract}

Keywords: environmental restrictions, convergence clubs, legal Amazon, stochastic kernels

JEL Classification: O47, R1 1

\title{
1. Introdução
}

Estudos recentes sobre a hipótese da convergência no Brasil, utilizando dados desagregados a nível municipal, mostram a formação de clubes de convergência entre os municípios brasileiros. Entre eles, destacam-se Laurini (2003), Gondim et al. (2004, 2007), Coelho (2006), Coelho e Figueiredo (2007), entre outros. Em geral, os resultados apontam para uma divisão regional da renda, o que reforça a ideia da necessidade de aprofundamento do debate sobre o efeito das políticas de desenvolvimento e de redução dos desequilíbrios regionais no Brasil.

Constata-se nesses estudos de uma dinâmica econômica interna aos clubes identificados em nível nacional, ou seja, uma dinâmica intrar- 
regional das rendas das economias, que possibilita a identificação de clubes de convergência dentro dessa escala geográfica. Isso é particularmente importante porque permite atacar o problema das desigualdades nos níveis de renda em uma escala sub-regional. Ademais, a utilização de condicionamentos complementa essa abordagem, permitindo identificar fatores que potencialmente estão ligados a trajetórias bem-sucedidas de crescimento econômico e quais concorrem na direção contrária.

Nas palavras de Coelho (2007), entender a natureza da dinâmica das rendas permite realizar inferência quanto ao efeito de choques na distribuição de renda alterando o ranking das rendas das economias. No caso da convergência condicional, apenas mudanças estruturais são capazes de alterar esse ranking, já que os choques só afetam o estado estacionário no curto prazo. Diferentemente, quando as economias se agrupam em clubes de convergência, que se caracteriza pela existência de múltiplos estados estacionários, um choque é capaz de deslocar uma economia de uma zona de atração para outra levando essa economia a um novo estado estacionário, afetando de forma permanente o ranking das rendas das economias.

No caso da Amazônia legal, esta é uma região que tem sua formação econômica marcada por ciclos econômicos de exploração de seus recursos naturais, cujo crescimento é fortemente influenciado por atividades produtivas voltadas para a exploração desses recursos. Desse modo, o crescimento econômico da região está condicionado não apenas pelos fatores tradicionais que afetam o crescimento das outras regiões do país, tais como o capital humano e o capital físico, entretanto, também é condicionado por outras variáveis ligadas à dinâmica de crescimento peculiar da região, tais como a exploração dos recursos naturais, ${ }^{1}$ representadas neste trabalho pelas variáveis socioambientais.

Isso posto, a finalidade deste artigo é verificar a existência de clubes de convergência com características socioeconômico-ambientais diferentes para os municípios da Amazônia legal, e determinar quais os principais condicionantes ambientais que contribuem para a formação destes clubes além dos condicionantes tradicionais, como, por

\footnotetext{
${ }^{1}$ Becker (2005) identifica três tipos de economias predominantes na região amazônica: a economia mineral, a economia da pecuária e madeireira e mais recentemente o agronegócio voltado para a produção de grãos.
} 
exemplo, capital humano etc. Para tanto será utilizada uma análise não paramétrica baseada em Quah (1993).

A justificativa para a utilização da análise não paramétrica nos estudos de convergência é fornecida por Quah $(1993,1997)$, que identifica pelo menos dois tipos de problemas das estimações tradicionais (de corte transversal): o primeiro problema é assumir que o coeficiente estimado é o mesmo para todas as economias. O segundo problema é conhecido como "Falácia de Galton", apontado por Friedman (1992) e Quah (1993), que mostra que o coeficiente negativo encontrado em regressões de crescimento pode não significar convergência, e sim um sintoma de uma regressão a média.

Por outro lado, a análise não paramétrica tem a vantagem de considerar a distribuição da renda como um todo, o que permite visualizar o comportamento dinâmico das economias em um período de tempo determinado. Quah (1997) afirma que a análise da dinâmica da distribuição de renda é eficiente para identificar a dinâmica intradistribuição e a mobilidade da distribuição das rendas das economias, mostrando, principalmente, a evolução dinâmica dessas distribuições.

O restante do trabalho está organizado da seguinte forma: na seção 2 analisa-se brevemente a relação entre a economia e o meio ambiente; na seção seguinte serão feitas algumas considerações acerca do crescimento econômico e o desmatamento na Amazônia legal; a seção 4 dedica-se a uma revisão da literatura sobre crescimento econômico e convergência; as seções 5 e 6 tratam da abordagem metodológica usada neste artigo; na seção 7 são descritos os resultados obtidos e, finalmente, na seção 8 são apresentadas as conclusões.

\section{Crescimento e Meio Ambiente}

A relação entre o crescimento econômico e meio ambiente já é amplamente discutida no âmbito da literatura sobre crescimento e desenvolvimento econômico (Anderson, 1972; Stiglitz, 1974; Dasgupta e Heal, 1974; Kamien e Schwartz, 1978; Dasgupta e Heal, 1979; Solow, 1992; Sachs e Warner, 1995; Grossman e Krueger, 1995; Hamilton, 1995; Gylfason et al. 1999; Gylfason 2001; Sachs e Warner, 2001; Barbier 2006; entre outros). 
Por outro lado, tem na abordagem do desenvolvimento sustentável (Bruntland, 1988) uma referência normativa para o tratamento dos efeitos do crescimento econômico insustentável sobre o estoque de recursos naturais no presente e a possibilidade dos seus efeitos sobre a disponibilidade futura desses recursos, bem como as consequências provocadas pelo esgotamento do capital natural em escala global.

Vale observar que essas preocupações surgem a partir da década de 70 , data em que, segundo alguns autores, os problemas ambientais ganham destaque na literatura e passam a ser tratados como uma consequência da intensidade da atividade econômica e do aumento da escala de intervenção humana sobre o meio ambiente (Mueller, 2007).

Destaquem-se nessa área as pesquisas recentes que utilizam a Curva de Kuznets Ambiental para estimar a relação entre o crescimento da renda per capita e a emissão de poluentes ou a depleção dos recursos naturais. Semelhante ao modelo original desenvolvido por Simon Kuznets, ${ }^{2}$ a Curva de Kuznets Ambiental (CKA) supõe que, inicialmente, haveria uma correlação positiva entre crescimento da renda per capita e emissão de poluentes. Com o avanço do desenvolvimento econômico, a relação se tornaria inversa a partir de um determinado ponto, tomando a forma de "U" invertido.

Estudos empíricos como de Selden; Song (1994), Shafik (1994), Arrow et al.(1995), Cole et al. (1997), Hilton; Stokey (1998), Andreoni; Levinson (1998), Harbaugh et al. (2000), Brock; Tayor (2004), Diniz et al. (2005), Arraes et al. (2006) apontam uma relação das variáveis ambientais com o crescimento econômico, com diferentes formatos, não exatamente evoluindo na direção desejável pela CKA. Já as variáveis que estão mais sujeitas ao monitoramento internacional ${ }^{3}$ têm apresentado um comportamento na direção de uma trajetória de desenvolvimento sustentável. Fonseca et al. (2005) encontra evidências da CKA para o Brasil, muito embora não tenha encontrado significância estatística para a preservação ambiental das proxys para o capital social e a desigualdade de renda.

Outras abordagens teóricas destacam os possíveis efeitos que o estoque de recursos naturais tem sobre o crescimento econômico de

\footnotetext{
${ }^{2}$ Nesse modelo o enfoque é a relação na forma de "U" invertido entre crescimento da renda per capita e desigualdade de renda.

${ }^{3}$ Os trabalhos mostram que a emissão de $\mathrm{CO}_{2}$ e o índice de mortalidade infantil apresentam resultados significativos corroborando com as previsões da CKA.
} 
longo prazo, constatando que os países com recurso abundante têm sofrido de uma espécie de "mal" que afeta essas economias, cujas principais características são as baixas taxas de crescimento econômico contrastando com os seus elevados estoques de riquezas naturais. Sachs e Warner $(1995,2001)$ mostram que os países com alta proporção de recursos naturais exportáveis em relação ao PIB tendem a ter uma taxa de crescimento mais baixa. Oliveira e Porto Junior (2004) mostram que, no curto prazo, os países com abundância de recursos naturais experimentam, inicialmente, uma aceleração de suas taxas de crescimento, mas no longo prazo esses países ou regiões não conseguem se beneficiar das vantagens comparativas oriundas do estoque de capital que possuem.

Os autores obtêm resultados significativos para a relação de longo prazo entre crescimento econômico e os níveis de utilização dos recursos naturais, corroborando com os resultados internacionais, mostrando que recursos naturais abundantes tendem a estar relacionados com baixas taxas de crescimento de longo prazo.

\section{Crescimento Econômico e Desmatamento na Amazônia Legal}

O crescimento econômico e o avanço do desmatamento na Amazônia legal, independente de qualquer relação causal, têm em suas trajetórias algumas semelhanças importantes. Essas semelhanças podem conduzir, à primeira vista, à crença da existência de uma correlação positiva entre o crescimento econômico e o avanço do desmatamento. Fearnside (2006) afirma que o desmatamento na Amazônia brasileira tem aumentado continuamente desde 1991, variando de acordo com as mudanças relacionadas às forças econômicas. No entanto, no período recente, observa-se que, apesar da manutenção da trajetória ascendente da taxa de crescimento da economia, vem ocorrendo uma queda na taxa de desmatamento da região. Essa nova dinâmica da relação entre o crescimento econômico e o desmatamento sugere a existência de outros fatores, tais como a relação entre as dinâmicas econômicas locais ligadas às oscilações do crescimento do mercado internacional (Ferreira, 2005), mostrando uma diferença entre o padrão de crescimento econômico do passado recente da região e o que vem ocorrendo no período atual. 
Amazônia legal vem apresentando um processo de aceleração de seu crescimento econômico. No período de 1996 a 2006 a região experimentou crescimento médio em torno de $7 \%,{ }^{4}$ bem acima da média nacional que foi de 3,3\% no mesmo período. Entretanto, apesar dessa trajetória ascendente de crescimento, o PIB da região ainda representa uma baixa proporção em relação ao PIB do Brasil, representando aproximadamente $8 \%$ do PIB nacional (Celentano, 2007).

Uma característica peculiar do crescimento econômico da Amazônia é a relação deste com a exploração dos recursos naturais da região, em especial, os recursos minerais e florestais. Este assunto tem sido objeto de inúmeros estudos, cujo foco principal está na identificação das causas e consequências do desmatamento e na preocupação com a preservação da biodiversidade.

As diferentes causas do desmatamento na Amazônia legal têm sido testadas por vários autores, apresentando resultados semelhantes, tais como os encontrados em Andersen et al. (2002), Soares-Filho et al. (2005), entre outros, que apontam a expansão dos meios de acesso à floresta e o avanço da agropecuária como as principais causas do desmatamento na Amazônia. Margulis (2003) mostra que a pecuária é a principal atividade econômica da região, e a viabilidade financeira desta é a fonte do processo dos desmatamentos da Amazônia brasileira, respondendo atualmente por cerca de $75 \%$ das áreas desmatadas na Amazônia legal e, juntamente com o extrativismo madeireiro, não fazem um uso socialmente ótimo da rica base de recursos naturais. Isso é evidente quando se observa as grandes distorções nos indicadores socioeconômicos, tais como a elevação da renda per capita, por exemplo, ${ }^{5}$ e grandes desigualdades presentes na região, principalmente no que tange à distribuição da renda e à qualidade de vida da população. Em resumo, é legítimo argumentar que os ganhos privados das atividades econômicas são largamente excludentes, pouco tendo contribuído para aliviar as persistentes desigualdades sociais e econômicas nitidamente observadas na região. Neste sentido, identificar as dinâmicas da trajetória de crescimento intrarregional na Amazônia é um poderoso instrumento para auxiliar a formulação de políticas mais eficientes de desenvolvimento regional. Novas estratégias de desenvolvimento podem ser utilizadas

\footnotetext{
${ }_{5}^{4}$ Dados do IPEA, disponíveis em www.ipeadata.gov.br

${ }^{5}$ O estado de Mato Grosso em 1970 tinha uma renda rural per capita de US\$ 424; em 1995 passou para US\$ 4.311. O Pará passou de US\$ 356 para US\$ 1.436, e Rondônia de US\$ 712 para US\$ 2.304. Mais detalhes em Margulis (2003).
} 
focalizando áreas que apresentem parâmetros comportamentais semelhantes e cujos condicionantes do crescimento econômico identificados permitam estimular o crescimento de forma mais eficiente, direcionando os investimentos para os fatores determinantes para a aceleração das taxas de crescimento econômico proporcionando o aumento do produto, do emprego e da renda regional.

\section{Revisão da Literatura}

Os estudos empíricos sobre convergência são bastante controversos, estando os seus resultados muitas vezes condicionados à amostra escolhida ou ao período de tempo analisado. Baumol (1986) conclui pela existência de convergência entre os países industrializados. De Long (1988) contesta as conclusões de Baumol (1986) apontando, dentre outros problemas, o viés de seleção na amostra dos países selecionados. O estudo clássico sobre convergência de Barro e Sala-i-Martin (1992) detecta a existência de convergência absoluta entre os estados americanos no período de 1840 a 1988, mas em nível mundial foi somente detectada convergência condicional, no período de 1960 a 1985. Sala-i-Martin (1996) obtém convergência absoluta e condicional para um grupo de países da OECD, bem como $\sigma$-convergência para as regiões dentro dos EUA e Japão, Alemanha, Reino Unido, França, Itália e Espanha.

Analisando um período mais longo, compreendido de 1870 a 1990, Pritchett (1997) também conclui pela inexistência de convergência a partir de uma amostra conjunta de países ricos e pobres. Recentemente, Jones (1997) e Quah (1997) verificaram que a distribuição mundial de renda per capita passou de unimodal para bimodal no período de 1960 para 1988. Bianchi (1997) analisa a hipótese da convergência da renda e confirma o surgimento de picos gêmeos (tradução da expressão cunhada por Quah "emerging twin peaks"). Essas evidências sinalizam a hipótese de existência de clubes de convergência em tornos de níveis de renda per capita diferenciada, ou seja, entre ricos e pobres.

Prosseguindo na trilha dos métodos não paramétricos para a análise da hipótese da convergência, cabe destacar a técnica denominada de classificação e clustering. Um dos trabalhos pioneiros nessa linha é o de Durlauf e Johnson (1995). Utilizando regression tree e as variáveis 
renda per capita e taxa de alfabetização como determinantes dos grupos, os autores encontram quatro clubes de países com dinâmicas de crescimento fundamentalmente distintas. Empregando essa mesma técnica, Johnson e Takeyama (2003) buscam determinar qual forma de convergência melhor descreve a dinâmica da renda dos estados norte-americanos, concluindo pela predominância da hipótese da convergência clube.

No Brasil, o estudo de convergência tem sido voltado para a busca da existência de $\beta$ e $\sigma$-convergência. A maioria dos estudos emprega as metodologias tradicionais como, por exemplo, regressões BarroBaumol e utilizam dados da renda em nível estadual pela dificuldade de obtenção de dados a um nível menos desagregado.

Assim por exemplo, Azzoni (1994) e Azzoni et al. (2000) concluem que não existem evidências de convergência para todos os estados brasileiros, sendo que nesse último surgem evidências de convergência condicional para capital humano, infraestrutura e variáveis geográficas entre 1981 e 1996. Ferreira e Diniz (1995) e Schwartzman (1996) encontram convergência absoluta para as rendas per capita dos estados brasileiros para o período entre 1970 e 1985. Zini Junior (1998), Ferreira (1999), Barossi e Azzoni (2003), encontram fraca convergência do início da década de 40 até meados da década de 90.

Recentemente os estudos de convergência têm avançado no sentido de incorporar novas metodologias de estimação, com a utilização de técnicas mais sofisticadas da econometria não paramétrica proposta por Quah (1993, 1997). De fato, Quah (1993) critica os estudos de convergência que utilizam as regressões do tipo Barro-Baumol, afirmando que a abordagem tradicional não era capaz de assimilar a dinâmica das distribuições de renda entre os países.

Segundo Quah (1993), as regressões tradicionais de convergência baseadas na renda inicial, seriam inadequadas para modelar a hipótese da convergência, devido apresentarem dois problemas principais: 1) assumir que o coeficiente estimado é o mesmo para todas as economias; 2) conhecido como "Falácia de Galton", apontado por Friedman (1992) e Quah (1993), que mostra que o coeficiente negativo encontrado em regressões de crescimento pode não significar convergência, e sim um sintoma de uma regressão à média. 
Ferreira (1998), Mossi et al. (2001), utilizando matrizes de transição de Markov e núcleos estocásticos, encontram evidências de convergência e formação de clubes de convergência entre os estados brasileiros. Magalhães (2001) não identifica convergência absoluta entre os estados brasileiros, encontrando evidências de spillovers geográficos e de formação de dois clubes de convergência: um nas regiões norte e nordeste e outro entre os estados do sul, sudeste e centro-oeste no período de 1986 e 1995.

Utilizando dados a nível municipal, Laurini et al. (2003) e Gondim et al. $(2004,2007)$ encontram evidências de uma distribuição regional da renda, identificando a formação de dois clubes de convergência no Brasil: um de baixa renda, formado pelos municípios das regiões Norte e Nordeste, e outro de alta renda, formado pelos municípios do Sul, Sudeste e Centro-oeste. Gondim et al. (2004, 2007) mostram que a educação e a localização geográfica são importantes condicionantes na formação de clubes de convergência, e as variáveis integração comercial e a desigualdade de renda não se mostraram determinantes para explicar as desigualdades entre os municípios brasileiros.

Coelho (2006), utilizando o método regression tree e testes de robustez, reforça a importância das condições iniciais na determinação da taxa de crescimento da renda dos municípios entre 1970-2000, e sugere a predominância da hipótese da convergência clube sobre as demais. Alencar (2005), usando um modelo threshold, verificou a existência de clubes de convergência no período de 1980 a 2000, identificando renda per capita e a taxa de analfabetismo como determinantes para formação dos clubes de convergência entre os municípios. Oliveira Júnior et al. (2007), utilizando um modelo threshold dados dos censos agrícola de 1970 a 1995, apontam para a formação de três clubes de convergência: um clube mais rico, formado por microrregiões do Sul e Sudeste, um clube intermediário formado, principalmente, pelas microrregiões do Norte e Centro-Oeste e, por fim, um clube mais pobre formado pelas microrregiões do Nordeste. Os resultados também mostraram que o capital físico é mais importante que o capital humano na explicação do processo de crescimento da agricultura brasileira. Paixão et al. (2008), seguindo o modelo teórico de Mankiw et al. (1992) e Durlauf e Johnson (1995), testaram a hipótese de convergência de renda para 237 municípios da Amazônia legal entre 1980-2004, e seus resultados indicaram a formação de 
seis clubes de convergência, distribuídos entre: dois mais ricos, com maior renda per capita; dois mais pobres, com menor renda per capita; e dois grupos intermediários. De modo geral, a proxy do capital humano mostrou-se significante para explicar o processo de convergência. No entanto, a proxy indicada para representar o investimento em capital físico, apesar de significante, apresentou-se negativamente correlacionada com o processo de crescimento da renda para quase todos os grupos.

\section{Abordagem não Paramétrica}

\subsection{Densidades não Paramétricas}

Inicialmente, a distribuição da renda per capita relativa será analisada através da utilização de funções de densidades de probabilidade estimadas através de funções de densidade de núcleo. Para evitar distorções nos resultados e os problemas inerentes à definição do tamanho do parâmetro $h$, conhecido como janela na função de densidade, neste trabalho será utilizada a regra de Silverman para um núcleo Gaussiano, que corresponde a 0.9 vezes o mínimo entre o desvio- padrão dos dados e a diferença entre o menor e o maior quartil dos dados, multiplicado pelo tamanho da amostra e elevando este valor à potência de $1 / 5$. Uma descrição completa desse tipo de estimação encontra-se em Silverman (1986), Laurini (2003) e Gondim (2004, 2007).

A análise das densidades de núcleo mostra o comportamento de renda relativa per capita dos municípios, indicando o que ocorreu com o conjunto da distribuição entre os períodos $t$ e $t+s$. O surgimento de várias modas no período $t+s$, contrastando com uma distribuição unimodal no período $t$, por exemplo, mostra que há grande dinâmica de transição entre o conjunto de economias analisadas e pode indicar a formação de clubes de convergência.

\subsection{Dinâmica de Transição Intradistribuição}

A análise da dinâmica de transição da distribuição da renda per capita relativa pode ser feita de duas formas: através da estimação da ma- 
triz de transição de Markov, no caso discreto, e através da estimação de Núcleos Estocásticos, para o caso contínuo. Para tanto, considerase que a evolução da distribuição da renda per capita relativa evolui como um processo de Markov de primeira ordem. Esta metodologia é semelhante à utilizada por Quah (1993, 1997) e Gondim (2004, 2007), que em seus trabalhos descrevem formalmente a Matriz de transição e a estimação de Núcleos Estocásticos.

A Matriz de transição consiste em dividir a distribuição de renda per capita relativa em intervalos, chamados de estados, cada um representando uma faixa de renda relativa. As células da matriz de transição estimam a probabilidade $P_{i j}$ do conjunto das economias pertencentes ao intervalo $i$ no período $t$ e que passaram para o estado $j$ no período $t+s$. Apesar de ser muito útil para identificar a mobilidade ocorrida na distribuição entre o período analisado, um problema inerente à estimação da matriz de transição é que os resultados são alterados de acordo com a definição dos intervalos determinados pelo pesquisador. ${ }^{6}$ Uma forma de superar isso é tornar a análise contínua através da estimação de densidades condicionadas estimadas não parametricamente através de uma função de transição chamadas de Núcleos Estocásticos.

Quah (1998) descreve formalmente a estimação dos Núcleos Estocásticos, de forma que aqui apresentaremos apenas um resumo da definição formal do modelo:

Definição: Sejam $M_{(u, v)}$ e $(R, \Re)$ espaços mensuráveis. Um Núcleo Estocástico em $(M, \mathfrak{R})$ é uma função $M_{(u, v)(y, A)} \times(R, \mathfrak{R}) \rightarrow[0,1]$ tal que:

a) para cada $y \in R, M(u, v)(y, A)$ é uma medida de probabilidade em $(R, \Re)$;

b) para cada $A \in \mathfrak{R}, M_{(u, v)}$ é uma função mensurável em $\mathfrak{R}$;

c) para cada $A \in \mathfrak{R}$, é válido $u(A)=\int M_{(u, v)}(y, A) d v(y)$.

As Condições "a" e "b" asseguram que o núcleo estocástico é um mapeamento bem definido para os espaços de probabilidade $M_{(u, v)}$ e $(R, \Re)$. A condição "c" define o conceito principal do núcleo estocás-

\footnotetext{
${ }^{6}$ Para uma descrição formal do modelo da matriz de transição, ver: Laurini (2003).
} 
tico: Dado um período inicial $t$, para uma dada renda $y$ existe uma fração $d v(y)$ de economias com renda próxima a $y$. No período $t+s$, uma parte das economias que contidas em $d v(y)$ irão se mover para um subconjunto $A \subseteq R$. Normalizando esta fração de economias pelo número total de economias, teremos a definição do núcleo estocástico $M(u, v)(y, A)$. A integral $\int M_{(u, v)}(y, A) d v(y)$ representa o total de economias que independente da renda inicial estarão no subconjunto A de economias no período $t+s$. Nesta integral, $M(u, v)(y, A)$ representa o total de economias que migraram de $y$ para $A$, e $d v(y)$ é a ponderação associada a cada $M(\cdot)$ dada pela distribuição marginal de $y$. Desta forma o núcleo estocástico pode ser visualizado como a forma contínua da matriz de transição, em que temos um contínuo de linhas e colunas, ou seja, formamos um contínuo de estados.

A análise do núcleo estocástico é feita através da observação da forma assumida pela distribuição expressa pela interseção das densidades condicionadas. Realizando cortes na distribuição e observando as curvas de nível produzidas por esses cortes, é possível analisar o deslocamento da massa do núcleo estocástico no período analisado. Se essa massa concentra-se ao longo do eixo diagonal, isso implica que independente do estado inicial das rendas per capita relativas do conjunto das economias, não houve transição para outros níveis de renda. A concentração da massa do núcleo estocástico paralela ao eixo vertical indica convergência, ou seja, independente da sua posição original, estaria ocorrendo uma aproximação às rendas per capita relativas das economias. Em contraste, uma concentração da massa da distribuição das rendas per capita relativas paralela ao eixo horizontal indicaria divergência com um distanciamento das economias do estado estacionário.

Para complementar a análise, também foram aplicados esquemas de condicionamento à distribuição original da renda per capita relativa. Da mesma forma que os núcleos estocásticos mostram a evolução da distribuição da renda per capita relativa ao longo do tempo, é possível ainda identificar um conjunto de variáveis de condicionantes que altera a distribuição da renda das economias através da utilização de esquemas de condicionamento. Quah (1997) e Gondim (2004, 2007) fazem uma definição formal dos núcleos estocásticos condicionados, apresentada de forma resumida na definição abaixo: 
Definição: Se $Y=\left\{Y_{\ell}(t): \ell\right.$ em $J$ e $\left.t \geq 0\right\}$ denotar as observações originais das rendas per capita relativas, define-se a versão condicional $Y^{c}=Y \mid S$ por:

$$
Y_{\lambda}^{c}(t) \equiv \frac{Y_{\lambda}(t)}{\sum_{j \in J^{\prime}(t)} \pi_{j}(t) Y_{j}\left(t-\tau_{\lambda}(t)\right)}
$$

A renda condicionada, $Y^{c}$, corresponde à renda per capita de $\ell$ relativa às das outras economias de $J^{\prime}$, apropriadamente ponderada. A interpretação é idêntica a dos núcleos estocásticos não condicionados, com a variável condicionante afetando a forma e o comportamento da massa do núcleo estocástico condicionante, cuja posição depende do esquema de condicionamento escolhido.

Neste artigo foram utilizados três grupos de variáveis condicionantes: capital humano, utilizando as variáveis "Anos de Estudo" e "Taxa de Analfabetismo"; variáveis ambientais, com as variáveis "Área Desmatada", "Rebanho Bovino" e "Área de Pecuária" e variáveis institucionais, com as variáveis "Índice de Gini", "Índice de Desenvolvimento Humano" e "Taxa de Dependência Fiscal". A escolha das variáveis dependeu, além da relevância das mesmas, já consagrada pela literatura, a disponibilidade em nível municipal no período de tempo analisado para o conjunto das economias observadas.

\section{Estimação}

\subsection{Variáveis Explicativas}

Neste artigo utiliza-se como variável dependente a renda municipal representada pelo PIB per capita relativo ${ }^{7}$ de uma amostra de 630 municípios da Amazônia legal observados no período de 1985 a 2007 a preços constantes de 2000, retirada da série de dados regionais do IPEA. A partir daí, foi criada a variável PIB relativo $(P I B r)$, que é o resultado da divisão do PIB per capita municipal pela média do PIB per capita da região.

\footnotetext{
${ }^{7}$ Uma definição mais detalhada sobre a análise do PIB per capita relativo será feita mais adiante na subseção 6.2 .
} 
As variáveis explicativas, chamadas de condicionantes, haja vista, serão utilizadas como pesos dentro dos esquemas de condicionamentos, ${ }^{8}$ foram divididas em 03 (três) grupos de variáveis: Capital Humano, Variáveis Institucionais e Variáveis Ambientais.

No grupo Capital Humano foram utilizadas a média de anos de estudo e a taxa de analfabetismo dos municípios da Amazônia legal para os anos de 1991 e 2000. No grupo das Variáveis Institucionais constam as variáveis: Índice de Gini, e Taxa de Dependência. As duas primeiras coletadas para os anos de 1991 e 2000, e a última calculada dividindo o total das Transferências Correntes pelo montante da Receita Orçamentária dos municípios no período de 1986 a 2005. Os dados foram extraídos das séries regionais do IPEA.

As variáveis ambientais usadas neste artigo foram a área desmatada nos anos de 1997 e 2007, o total do rebanho bovino nos anos de 1985, 1996 e 2007, e a área total de pecuária nos anos de 1985, 1996 e 2007, todos os dados na escala municipal extraídos da série do IPEA.

Para a construção dos esquemas de condicionamento, primeiramente, foi construída uma matriz de vizinhança $W, \mathrm{n} \times \mathrm{n}$, com $\mathrm{n}$ áreas $\left(A_{1} \ldots \ldots . . A_{n}\right)$, onde cada elemento $w_{i j}$ representa a posição de um vizinho $j$ geográfico contíguo de $i$.

$\mathrm{Na}$ estimação, cada entrada de dado é transformada em um peso, $\omega_{i j}$, que representa uma relação entre as variáveis $\mu_{i}$ e $\mu_{j}$, observadas dos municípios $i$ e $j$, de modo que $\pi_{i j}=w_{i j}\left(\omega_{i j}\right)$ é o valor resultante atribuído a cada entrada da matriz de vizinhança. Utilizando o comando de programação adequado na estimação, ${ }^{9}$ a matriz de transição contínua, $M_{l}$ (núcleo estocástico) é então devidamente ponderada pela matriz de pesos não normalizada $W_{i j}$, produzindo o núcleo estocástico condicionado, ou seja, $M_{l}^{c}$. Como não existe uma rotina adequada capaz de produzir a matriz $W_{i j}$, cada linha de $W_{i j}$ para as relações $\omega_{i j}$ deve ser calculada individualmente para cada $\mu_{i}$ e $\mu_{j}$, observado exigindo um enorme esforço na sistematização das ponderações, o que dificulta o trabalho de estimação, especialmente para amostras grandes. Isso talvez explique, inclusive, o reduzido número de trabalhos usando esta metodologia.

\footnotetext{
${ }^{8}$ Gondim $(2004,2007)$ descreve a construção de pesos para esquemas de condicionamento.

${ }^{9}$ Para um estudo mais detalhado, consultar The TSRF Reference Manual, Quah (2000).
} 


\subsection{Densidades e Núcleos Estocásticos Incondicionados}

A figura abaixo apresenta as densidades do PIB per capita relativo à média regional dos municípios da Amazônia legal, denotados a partir deste ponto como PIBr. Como descrito na subseção anterior, esse indicador é calculado a partir do PIB per capita dos municípios, dividido pela média dos PIBs per capita da região. Desse modo, um $P I B r$ igual a 1 corresponde à média do PIB per capita da região; 0,5 corresponde à metade da média e 2,0 corresponde ao dobro da média do PIB per capita regional e assim por diante. Observa-se na análise das densidades do $P I B r$, que uma curva mais concentrada em torno do ponto 1.0 (leptocúrtica) indica uma maior convergência, ao passo que uma curva mais achatada (platicúrtica) indica maior dispersão das rendas, portanto, maior divergência.

A evolução das densidades do $P I B r$ dos municípios da Amazônia legal, estimadas utilizando um núcleo Gaussiano, Figura 1, mostra o comportamento da renda per capita relativa nos anos de 1985, 1996, 2000 e 2007. Observa-se que ao longo do tempo houve um aumento da concentração dos municípios em torno da média do $\mathrm{PIBr}$ da região. Em geral, percebe-se que, no período final a distribuição assume uma característica multimodal, descartando a hipótese de convergência absoluta, apresentando evidências da formação de clubes de convergência. É possível identificar que as economias agrupam-se em cinco grupos de renda em torno das modas situadas nos intervalos de 0.0 a $0.8,0.8$ a 1.9, 1.9 a 2.7, 2.7 a 3.7 e acima de 3.7. Nota-se ainda formação de uma longa calda que se estende à direita da distribuição, indicando um aumento dos municípios com renda relativa acima do ponto 4.0 (vezes) a renda média da região.

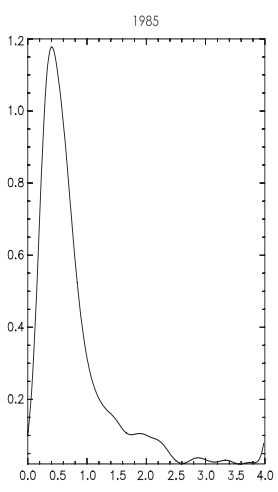

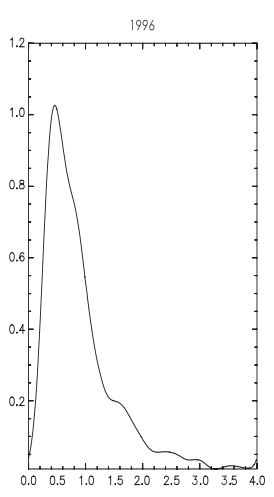

b

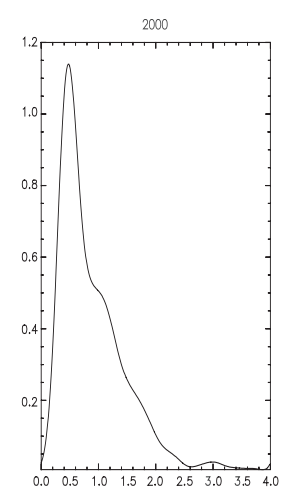

C

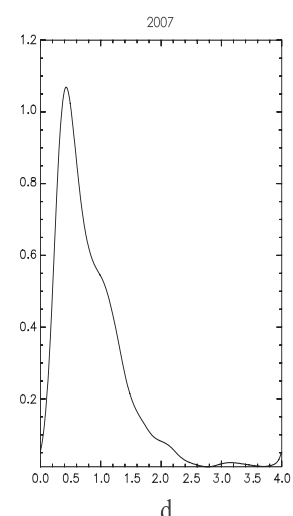

Fig.l- Densidades de Núcleo do PIBr dos Municípios da Amazônia Legal-1985 a 2007

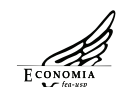


A análise da matriz de transição mostra a probabilidade das transições ocorridas no interior da distribuição do $\mathrm{PIBr}$ dos municípios da Amazônia legal. Utilizando os intervalos de renda definidos pela análise das densidades de núcleo, percebe-se que há um aumento da concentração das economias em torno da renda média da região (segundo estado da matriz), além de uma probabilidade muito forte de permanência no estado de renda mais baixa da distribuição. Cerca de $83 \%$ das economias que estavam de renda baixa (abaixo da média regional) no período inicial permaneceram no mesmo estado, $15 \%$ fizeram a transição e cerca de $1 \%$ apenas passaram para níveis mais elevados de renda. No outro extremo, mais da metade das economias de renda alta no período inicial transitaram para níveis mais baixos de renda; destas, cerca de $24 \%$ aproximaram da média da renda regional.

Quadro 1 - Matriz de Transição - PIBr dos Municípios da Amazônia Legal - 1985 a 2007 - Transição de 20 anos

\begin{tabular}{|c|c|c|c|c|c|c|c|}
\hline \multicolumn{8}{|c|}{ PIBr - Transição de 20 anos } \\
\hline \multicolumn{8}{|c|}{2007} \\
\hline \multirow{6}{*}{$\begin{array}{l}\stackrel{\circ}{\circ} \\
\stackrel{\circ}{\leftarrow}\end{array}$} & \multicolumn{2}{|c|}{ Intervalos } & $-\infty-0.8$ & $0.8-1.9$ & $1.9-2.7$ & $2.7-3.7$ & $3.7-+\infty$ \\
\hline & $-\infty-0.8$ & 344 & 0.83 & 0.15 & 0.01 & 0.01 & 0.01 \\
\hline & $0.8-1.9$ & 215 & 0.29 & 0.65 & 0.04 & 0.01 & 0.01 \\
\hline & $1.9-2.7$ & 32 & 0.03 & 0.66 & 0.19 & 0.06 & 0.06 \\
\hline & $2.7-3.7$ & 13 & 0.00 & 0.46 & 0.31 & 0.00 & 0.23 \\
\hline & $3.7-+\infty$ & 17 & 0.00 & 0.24 & 0.24 & 0.12 & 0.41 \\
\hline \multicolumn{3}{|c|}{ Ergodic distribution: } & 0.590 & 0.342 & 0.033 & 0.014 & 0.020 \\
\hline
\end{tabular}

O núcleo estocástico estimado do $\mathrm{PIBr}$ confirma as evidências de convergência entre os municípios da Amazônia legal. É possível visualizar na Figura 2 o que ocorreu com a distribuição do $\mathrm{PIBr}$ em três períodos de transição de 10,15 e 20 anos. A massa do núcleo estocástico desloca-se ao longo do tempo e posiciona-se próximo ao eixo vertical, indicando que independente da posição inicial, as economias concentram-se em grupos de renda, sendo o mais relevante deles o que se situa acima da média da renda regional com baixa probabilidade de transição dos grupos de economia de renda baixa. 

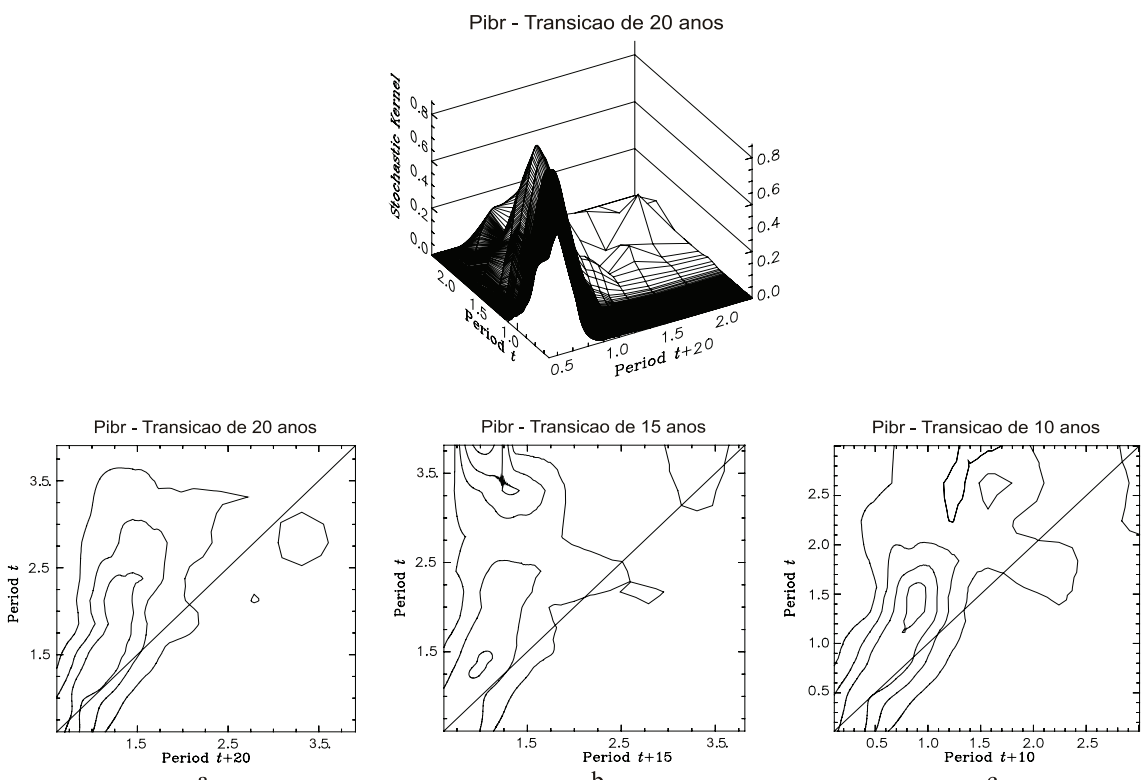

Fig. 2 - Núcleo Estocástico-PIBr dos Municípios da Amazônia Legal - Transição de 10,15 e 20 anos

Os gráficos mostram ainda que existem quatro áreas de concentração de renda com as mais significativas em torno dos intervalos até 0.8 e 1.9 vezes a renda média regional, confirmando a formação de três clubes de convergência, um formado pelos municípios com renda baixa, outro com municípios de renda média e outro com os municípios com renda alta com $P I B r$ acima de 2.7 vezes a média da renda da região. Este resultado confirma as evidências anteriormente levantadas pela análise discreta que mostrava uma tendência de baixa probabilidade de transição das economias de renda baixa e alta, bem como a formação de clubes de convergência entre os municípios da Amazônia legal.

\subsection{Densidades e Núcleos Estocásticos Condicionados}

\section{Condicionamento pelo Capital Humano}

A importância do capital humano para o crescimento e para o desenvolvimento econômico tem sido amplamente discutida pela literatura. 
O modelo de Lucas (1988) produziu um arcabouço teórico que permitiu associar um maior nível de capital humano com maiores taxas de crescimento de longo prazo. Romer, Mankiw e Weil (1992) constroem um modelo em que a acumulação de capital humano é muito similar à acumulação de capital físico no modelo de Solow, o que torna os dois modelos bastante parecidos, mostrando que quanto mais recursos dedicados à acumulação de capital, considerado no seu sentido mais amplo, maior será o produto que será produzido no futuro. Um alto índice de escolaridade é um indicativo de trabalhadores com maiores habilidades e maior produtividade, o que por sua vez aumenta a capacidade de produção de bens e serviços de uma economia. A abundância de recursos humanos bem-educados também facilita a absorção e a produção de tecnologia.

Através da aplicação do esquema de condicionamento do $\mathrm{PIBr}$ pelo capital humano, foram estimadas as densidades de núcleos e os núcleos estocásticos condicionados, cujo resultado pode ser visualizado nas Figuras 3, 4 e 5. Os Gráficos $3 a$ e $3 b, 3 c$ e $3 d$ mostram a evolução da densidades condicionadas da variável Anos de Escolaridade nos 1985 e 2007 e Taxa de Analfabetismo, respectivamente.

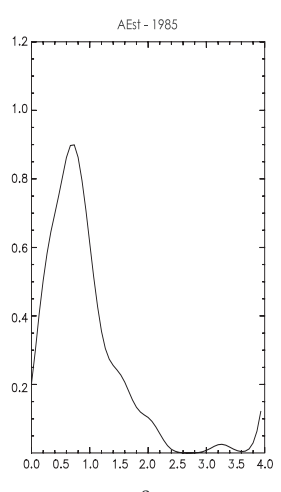

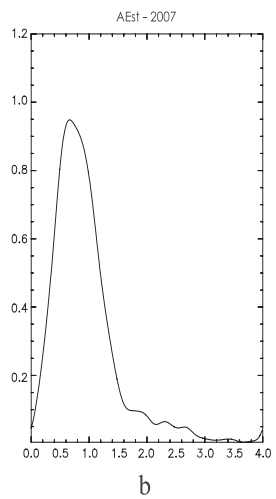
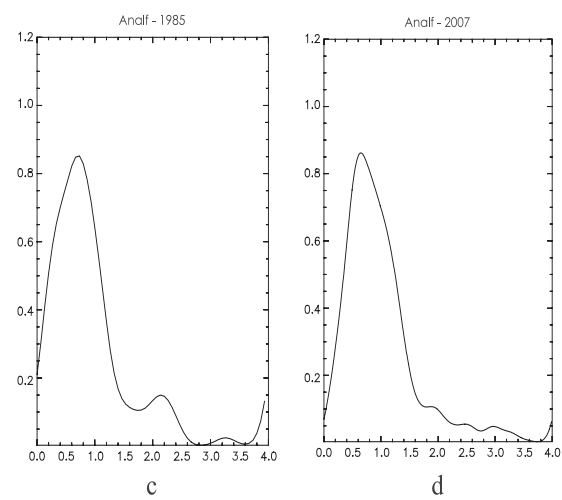

Fig. 3 - Densidades de Núcleo Condicionadas pelo Capital Humano - 1985 e 2007

Nota-se em $3 a$ e $3 b$ uma sensível redução da dispersão das rendas condicionadas em relação à distribuição original, em contraste com o que ocorre nos Gráficos $3 c$ e $3 d$, nos quais a dispersão aumenta, tanto comparando 2007 com 1985 quanto em relação à distribuição original, indicando convergência condicionada pela variável escolaridade. 


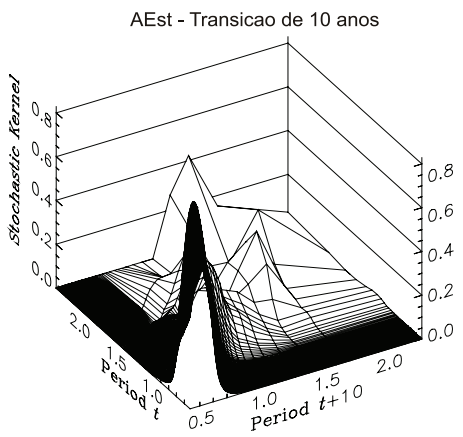

a

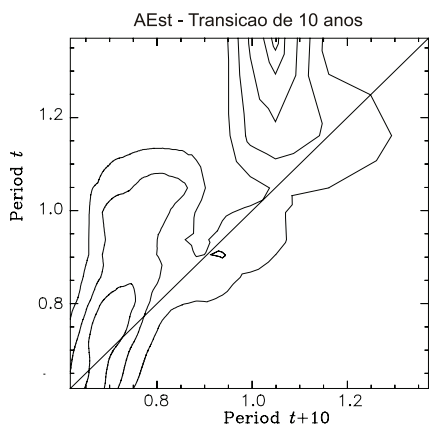

$\mathrm{b}$

Fig. 4 - Núcleo Estocástico Condicionado - Anos de Estudo - 1997 a 2007 Transição de 10 anos

O núcleo estocástico condicionado revela que a média de anos de estudo, estimado para uma transição de 10 anos, ${ }^{10}$ apresenta um padrão de convergência condicionada pela escolaridade. A massa do núcleo estocástico posiciona-se paralelo ao eixo vertical (Gráfico $4 b$ ), confirmando as evidências apresentadas pelas densidades de núcleo condicionadas. É preciso observar que há uma parte da distribuição da renda relativa situada em torno do eixo diagonal, indicando que para um grupo de economias, em torno da média regional, há fraca convergência condicionada pela escolaridade.

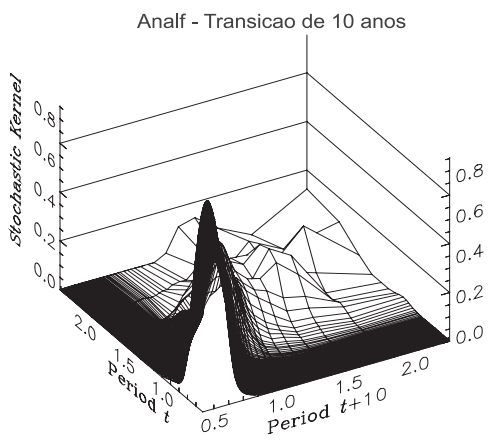

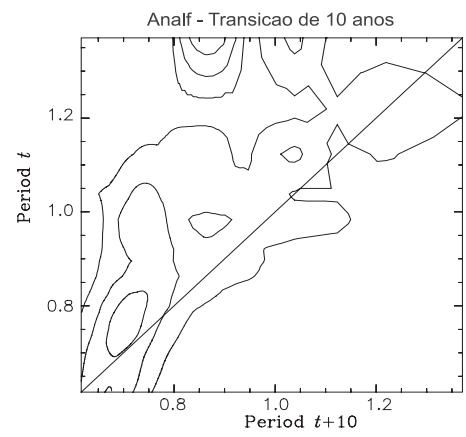

b

Fig. 5 - Núcleo Estocástico Condicionado - Analfabetismo - 1997 a 2007 Transição de 10 anos

\footnotetext{
${ }^{10}$ Os dados originais são de 1991 e 2000. Neste caso, optou-se por estimar uma transição a partir da série original, de 1997 a 2007 com um lag de 1 ano.
} 
A evolução do núcleo estocástico condicionado pela Taxa de Analfabetismo confirma as evidências apresentadas pelas densidades de núcleo. O Gráfico $5 b$ mostra que grande parte da distribuição condicionada situa-se ao longo do eixo diagonal com uma sensível inclinação paralela ao eixo vertical, indicando apenas fraca convergência.

A evolução da renda relativa condicionada confirma as evidências de convergência e a formação de clubes de convergência condicionada pelo capital humano. A análise dos núcleos estocásticos revela que a média de anos de estudo é mais importante para o crescimento econômico dos municípios com renda relativa acima de 1.5 vezes a média regional (ver Gráfico $4 b$ ). Já a taxa de analfabetismo parece ser mais importante para economias do clube de convergência de renda baixa nos quais predominam atividades econômicas que utilizam a mão de obra menos qualificada, o que pode ser visualizado no Gráfico $5 b$.

\section{Condicionamento por Variáveis Institucionais}

Estudos recentes de crescimento têm se preocupado com a contribuição de aspectos institucionais tais como nível de desigualdade, qualidade das instituições, baixa presença do governo, ausência de democracia, entre outros, como fatores capazes de afetar o crescimento econômico. Alguns estudos empíricos ${ }^{11}$ encontram evidências de que a desigualdade de renda tende a retardar o crescimento nos países pobres e aumentar o crescimento em países ricos. ${ }^{12}$ Outros estabelecem uma relação positiva entre os gastos do governo, produtividade do setor privado e crescimento econômico. Barro (1990) propõe a divisão entre gastos produtivos, que afetam positivamente o crescimento econômico de longo prazo e os gastos improdutivos, que não afetam o crescimento econômico. Na abordagem da Nova Geografia Econômica, os gastos públicos locais podem ser produtivos e, por consequência, afetar o crescimento econômico da localidade. Gastos em infraestrutura, educação e saúde, que fazem parte da

\footnotetext{
${ }^{11}$ Barro (2000) analisa a influência da desigualdade de renda no crescimento econômico dos países. ${ }^{12}$ Este resultado é compatível com a curva de Kuznets, cujas principais conclusões são que a fase inicial do crescimento é marcada por altos níveis de desigualdade, mas que esta tende a reduzir no longo prazo.
} 
política fiscal local, podem afetar a produtividade do setor privado e estimular o crescimento da economia local.

Para testar o efeito das variáveis institucionais no crescimento econômico, foram utilizadas as variáveis Índice de Gini e Taxa de Dependência Fiscal dos Municípios. A evolução da renda relativa condicionada mostra que para os anos de 1996, 2000 e 2007 há uma concentração da distribuição em torno da média regional. A Densidade condicionada pelo Índice de Gini apresenta aumento da dispersão de cerca de $20 \%$ e a Taxa de Dependência Fiscal em cerca de $31 \%$, em relação à distribuição original, o que fornece indícios de fraca convergência e divergência respectivamente.
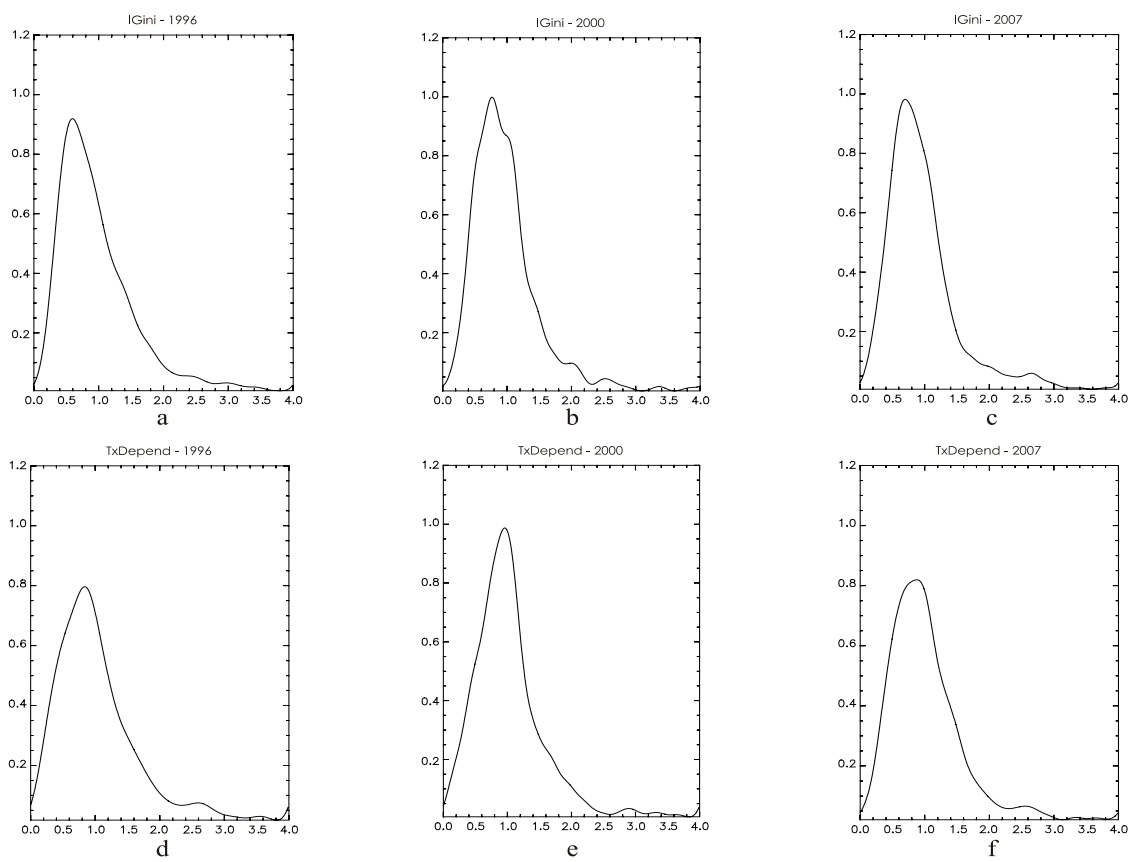

Fig. 6 - Densidades de Núcleo Condicionadas - Índice de Gini e Taxa de Dependência - 1996, 2000 e 2007

A estimação do Núcleo Estocástico condicionado pelo Índice de Gini confirma a evidência apresentada pela evolução das densidades condicionadas. Como pode ser visualizado na Figura 7, o núcleo estocástico encontra-se concentrado ao longo do eixo diagonal e muda 
sua trajetória somente a partir do ponto 2.5 vezes a média da renda regional, indicando que a desigualdade afeta o crescimento econômico das economias situadas no clube de convergência com renda acima da média regional, confirmando que, para uma transição de 10 anos, há somente fraca convergência condicionada.

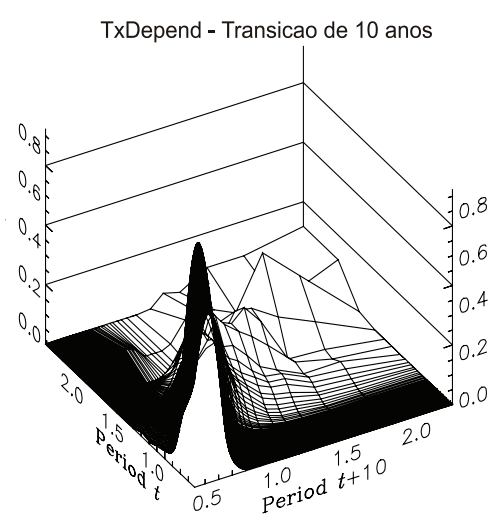

a

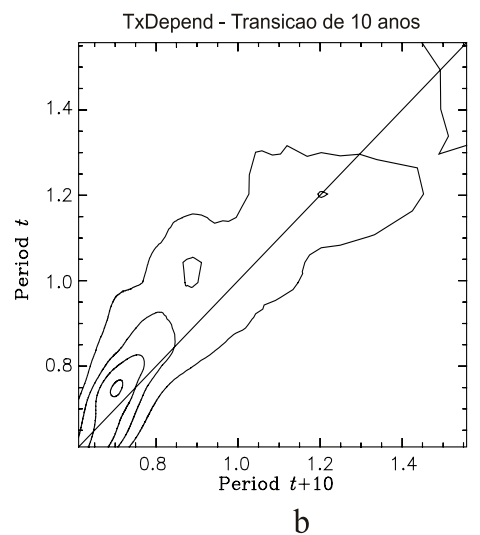

b

Fig. 7 - Núcleo Estocástico Condicionado - Índice de Gini - 1996 a 2007 Transição de 10 anos

A Figura 8 mostra que a Taxa de Dependência Fiscal não produz qualquer efeito sobre o crescimento dos municípios. Como pode ser visualizada no Gráfico $8 b$, a massa do núcleo estocástico concentrase em torno do eixo diagonal. Para uma transição de 10 anos, não há convergência condicionada pela dependência financeira de transferências. Os municípios da Amazônia apresentam elevado grau de dependência dos recursos de transferências, representando um importante componente da receita orçamentária dessas economias. O fato desses recursos não proporcionarem efeitos positivos sobre o crescimento econômico pode estar ligado ao padrão da aplicação dessas transferências, que mesmo em municípios de renda média, é usado no grupo das despesas correntes, ou seja, na manutenção do funcionamento da administração pública em detrimento das despesas de investimento em infraestrutura, por exemplo, que possui efeitos econômicos e gera externalidades para o desenvolvimento das atividades econômicas em nível local, conforme previsto por Barro (1990). 

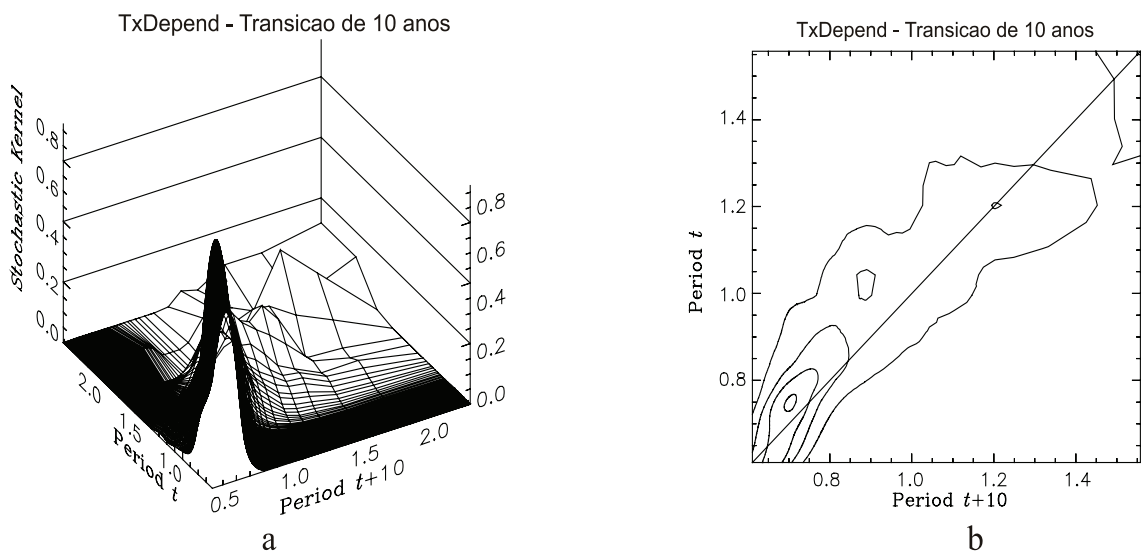

Fig. 8- Núcleo Estocástico Condicionado - Taxa de Dependência - 1996 a 2007 Transição de 10 anos

Dada a complexidade do tema, tanto os efeitos da desigualdade como do grau de dependência dos municípios sobre o crescimento econômico carecem de uma maior investigação para que possam ser gerados resultados mais robustos e conclusivos.

\section{Condicionamento por Variáveis Ambientais}

As variáveis ambientais são introduzidas na literatura através da abordagem do desenvolvimento sustentável que traz consigo a preocupação à utilização intertemporalmente viável dos recursos naturais devido ao fato de que estes são finitos e, em grande parte, não renováveis.

A utilização das variáveis ambientais Área Desmatada, Área de Pecuária e Rebanho Bovino neste trabalho constitui uma inovação em estudos de crescimento econômico e representam esforço para entender de que maneira a dinâmica do crescimento econômico regional está relacionado à exploração dos recursos naturais de um determinado espaço econômico particular. Isto é pertinente em uma região geográfica ou econômica, na qual o crescimento é conduzido por atividades ligadas à exploração dos recursos naturais, onde não há consenso sobre a relação de causa e efeito entre as variáveis econômicas e ambientais apesar do esforço de vários pesquisadores que 
militam em torno desta pauta. A utilização das variáveis ligadas à pecuária se justifica pelo fato de que esta atividade econômica está intimamente ligada à degradação ambiental da região, já que sua expansão se dá em áreas de desmatamento que são convertidas em pastagens. $^{13}$

Na Figura 9 é apresentada a evolução das densidades de núcleo estimadas para os anos de 1997 e 2007. Nelas é possível notar que não há evidências de convergência condicionada pelo desmatamento, haja vista a densidade condicionada apresentar maior dispersão da renda relativa municipal em relação à distribuição original.
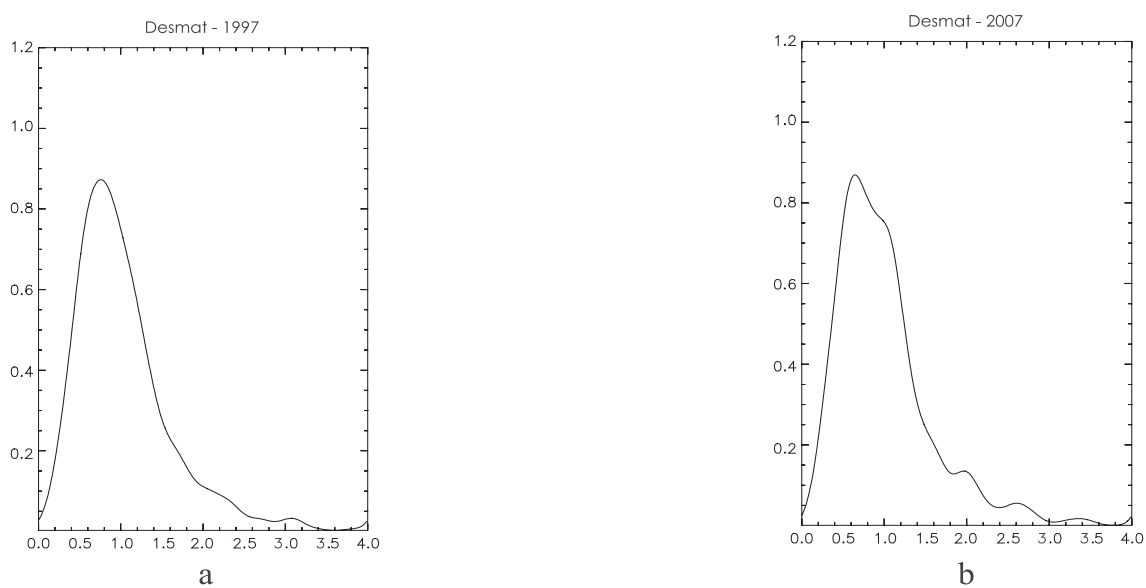

Fig. 9 - Densidades de Núcleo Condicionadas - Área de Desmatamento - 1997 e 2007

A estimação do núcleo estocástico condicionado confirma as evidências de que o desmatamento não é determinante para o crescimento econômico dos municípios da Amazônia legal. A massa do núcleo estocástico posiciona-se em torno do eixo diagonal indicando que, independentemente do período inicial, as rendas condicionadas não se alteram ao longo do período de transição. Além disso, há um aumento de 39\% na dispersão da renda relativa condicionada em relação à distribuição não condicionada, revelando que o desmatamento tem provocado o distanciamento das economias de seu ponto de estado estacionário.

\footnotetext{
${ }^{13}$ Para uma discussão mais detalhada, ver Margullis (2003), Rivero et al. (2009), entre outros.
} 

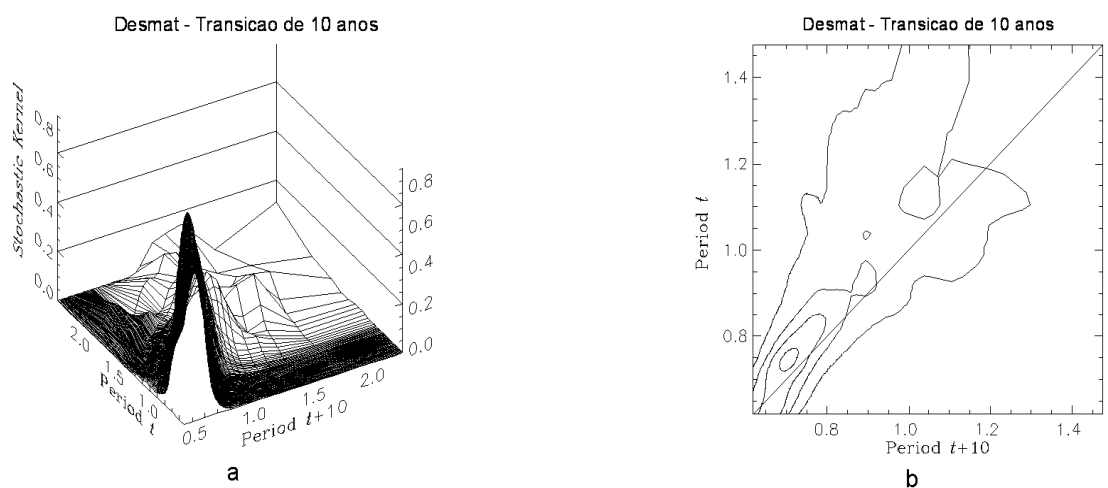

b

Fig. 10 - Núcleo Estocástico Condicionado - Área de Desmatamento - 1997 a 2007 Transição de 10 anos

A estimação das densidades condicionadas pelas variáveis Área de Pecuária e Rebanho Bovino apresentaram evidências de fraca convergência como pode ser visualizado na Figura 10. A evolução da renda relativa condicionada apresenta sensível redução da dispersão, indicando que as variáveis analisadas afetam o crescimento econômico das economias municipais.
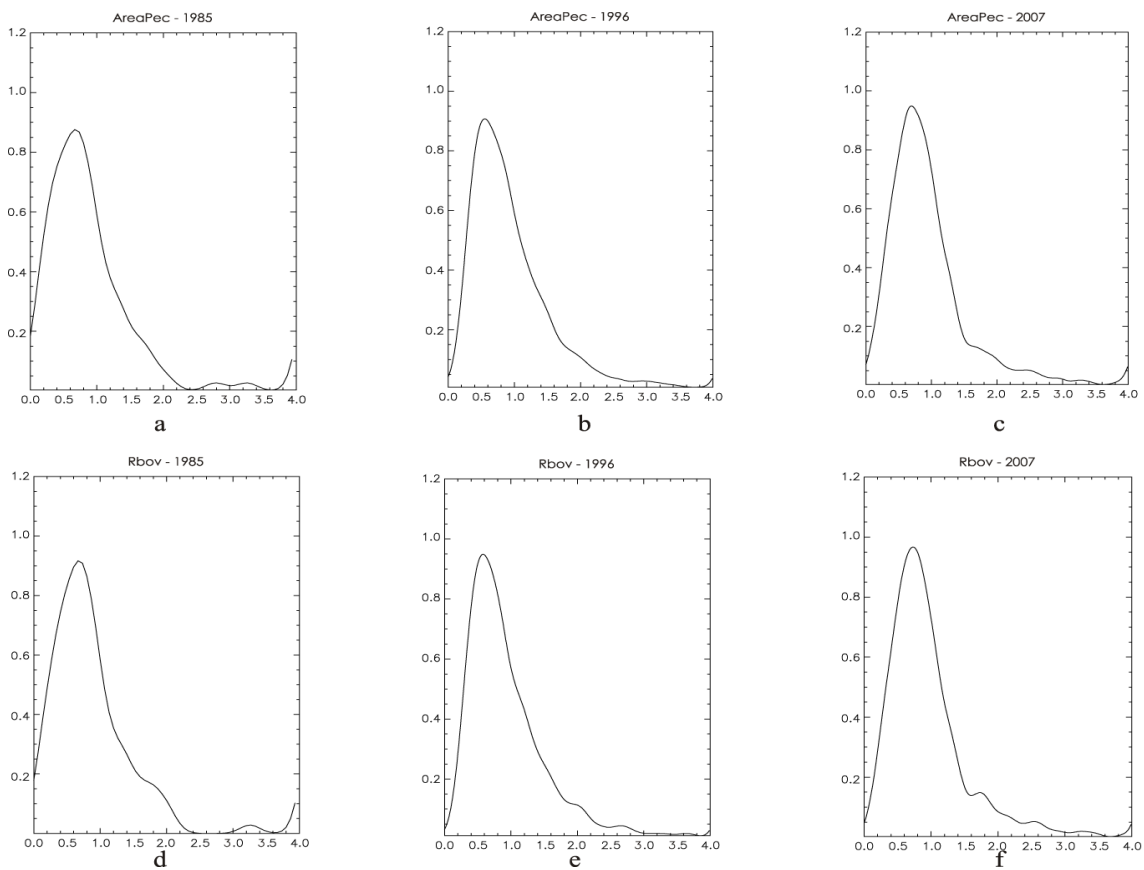

Fig. 11 - Densidades de Núcleo Condicionadas pela Área de Pecuária e Rebanho Bovino -1985 -2007 
Os núcleos estocásticos condicionados mostram evidências de fraca convergência condicionada pela Área de Pecuárias num período de transição de 10 anos, especialmente para as economias situadas acima da média da renda regional. $\mathrm{O}$ mesmo padrão é observado para o esquema de condicionamento pelo Rebanho Bovino, que afeta o crescimento econômico apenas das economias situadas acima da renda média regional, enquanto que as economias de renda baixa tendem a não serem impactadas por esta variável no período de transição analisado.

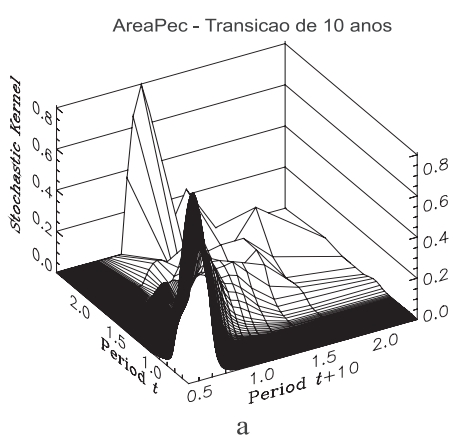

Área de Pecuária

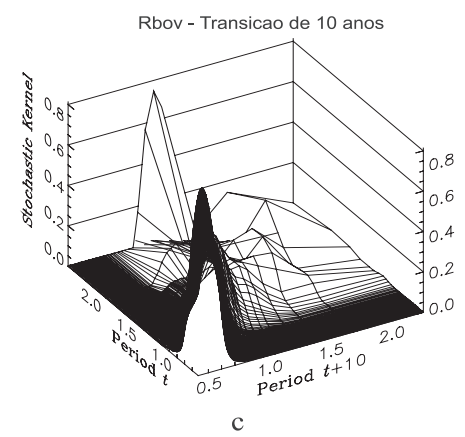

\section{Rebanho Bovino}

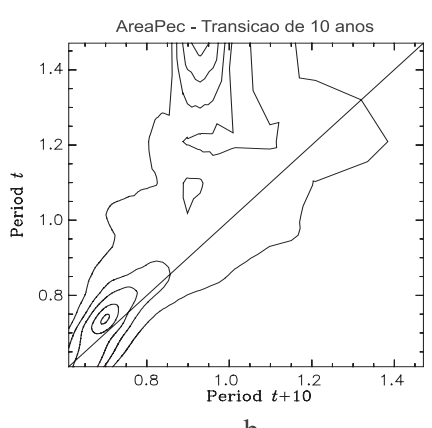

b

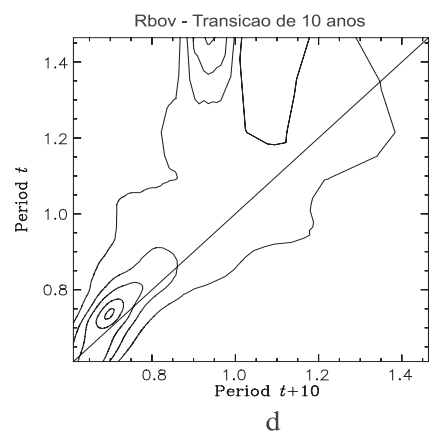

Fig. 12 - Núcleo Estocástico Condicionado - Área de Pecuária e Rebanho Bovino 1996 a 2007 - Transição de 10 anos

As evidências de fraca convergência observada na estimação dos núcleos estocásticos condicionados pelas variáveis área de pecuária e rebanho bovino corrobora com os resultados já encontrados na literatura que apontam a pecuária como uma das atividades econômicas mais dinâmicas e de maior impacto da região. A expansão desta ati- 
vidade no período recente se dá graças à alta liquidez, à simplicidade do processo produtivo e ao baixo nível de investimento de capital para implantação (Rivero et al. 2009). Umas das características importantes da pecuária é a sua baixa produtividade, baixa agregação de valor e de geração de emprego (Schineide et al. 2000). Ressalte-se ainda que os 10 municípios que possuem os maiores rebanhos bovinos apresentam baixas taxas de crescimento do PIB per capita, o que pode estar por traz dos resultados das estimações apresentadas neste artigo. A fraca convergência apresentada para municípios com renda acima da média regional evidencia um novo padrão da expansão desta atividade econômica na região que, graças ao aumento da demanda global provenientes tanto do mercado interno como do mercado externo, vem apresentando elevadas taxas de crescimento. Outros fatores, como a estabilidade econômica e a disponibilidade de áreas livres para ocupação também são relevantes para justificar seus efeitos no crescimento dos municípios com renda relativa acima de 1.2 vezes a média da renda regional.

\section{Conclusões}

Seguindo as tendências recentes dos estudos empíricos de crescimento, foi utilizada neste artigo a metodologia proposta por Quah (1993, 1997) e utilizada por Laurini (2003), Gondin (2004) e Coelho (2006), que estimam a convergência através da análise não paramétrica da distribuição de renda com a estimação de densidades de núcleos e núcleos estocásticos, cuja finalidade foi identificar clubes de convergência entre os municípios da Amazônia legal, bem como os principais condicionantes do crescimento econômico da região.

Os resultados mostraram evidências de convergências entre os municípios da Amazônia legal. A evolução da renda relativa municipal no período de 1985 a 2007 mostra que a distribuição apresenta característica multimodal, evidenciando a formação de três clubes de convergência: um de renda baixa, um de renda média e outro de renda alta. A distribuição apresenta ainda uma tendência de baixa probabilidade de transição dos municípios mais pobres (clube de renda baixa) evidenciando que, ao longo do período analisado, essas economias têm baixa probabilidade de alcançar níveis mais elevados de renda. 
No intuito de identificar quais fatores são os determinantes para o processo de crescimento dos municípios da região, foram aplicados esquemas de condicionamentos utilizando três grupos de variáveis: capital humano, variáveis institucionais e variáveis ambientais. Os resultados mostram que o capital humano, medido pela taxa de analfabetismo e anos de escolaridade são significantes para o crescimento econômico dos municípios. As variáveis ambientais área de pecuária e efetivo do rebanho bovino apresentaram apenas fraco condicionamento, sendo relevantes para as economias com renda relativa acima de 1.2 vezes a renda média regional, enquanto as variáveis institucionais Índice de Gini e Taxa de dependência e a variável ambiental área de desmatamento não são significantes para explicar a dinâmica das economias da região.

Os resultados encontrados mostram a importância do investimento na educação como indutor do crescimento econômico dos municípios da região. O forte condicionamento encontrado para as economias com renda acima de 1.9 vezes a renda média regional indica que há uma maior demanda de mão de obra mais qualificada especialmente nos setores que exigem maior absorção de tecnologia e maior produtividade. O fraco condicionamento encontrado para as variáveis área de pecuária e rebanho bovino evidenciam que as características fundamentais desta atividade econômica afetam negativamente o crescimento econômico dos municípios da Amazônia legal. A baixa rentabilidade, ainda evidenciada pela pecuária na região, aliadas ao pequeno impacto na geração de empregos e à baixa necessidade de investimento em capital, explicam a expansão experimentada por esta atividade na Amazônia legal no período recente, e podem ser responsáveis pela fraca significância das variáveis correlacionadas à pecuária para o crescimento da renda da região. Uma análise comparativa entre o ranking dos municípios com maior efetivo do rebanho bovino e a evolução do produto mostra que os 10 municípios com os maiores rebanhos apresentam baixas taxas de crescimento, corroborando o argumento anterior. Vale observar, entretanto, que apesar de significativos, esses indícios carecem de uma investigação mais aprofundada para a obtenção de resultados mais conclusivos.

Outro importante resultado evidenciado neste artigo diz respeito à constatação de que o desmatamento não é significante para o crescimento econômico dos municípios da Amazônia. Na verdade este resultado aponta para uma relação inversa entre níveis de desmata- 
mento e renda per capita. A comparação entre as cinco primeiras posições no ranking do PIB per capita e as posições no ranking do desmatamento revela que os municípios com as maiores rendas per capita apresentaram as menores taxas de desmatamento em 2007. O inverso também ocorre: os cinco primeiros municípios com as maiores taxas de desmatamento anual apresentam baixos níveis de rendas per capita. Esses resultados revelam indícios de que o desmatamento está associado a baixos níveis de renda, e não o contrário, mostrando ainda que, além de trazer sérios danos ao meio ambiente local, o desmatamento não tem efeitos positivos no crescimento econômico e na redução das desigualdades entre os municípios da Amazônia.

Neste sentido, os resultados obtidos demonstram a importância das condições iniciais, em especial do estoque de capital humano, na determinação dos níveis de renda de longo prazo dos municípios. O investimento em educação e na qualificação profissional é fundamental para o crescimento econômico e para a criação e absorção de tecnologia na Amazônia. As estimações revelam que os municípios de renda média e alta, nos quais as atividades econômicas exigem uma maior produtividade, são condicionados por maiores níveis de escolaridade, enquanto que as economias de renda baixa, onde prevalecem atividades econômicas de baixa produtividade, sensíveis alterações nos níveis educacionais básicos afetam o crescimento econômico. Estratégias para melhorar a eficiência dos investimentos em educação básica nos municípios membros do clube de renda baixa e elevar os níveis de produtividade da mão de obra nos clubes de renda média e alta, alterações no padrão de crescimento da pecuária, através da intensificação da produção, na implementação de tecnologia e na verticalização da cadeia produtiva são o ponto de partida para ampliar o crescimento econômico e aumentar o produto, a geração de empregos para a internalização da renda e criar as condições necessárias para a superação dos gargalos ainda presentes na região.

\section{Referências}

Alencar, F. (2005) Searching for socioeconomic patterns in the Brazilian Municipalities; An analysis of Club Convergence. Texto para Discussão.

Anderson, Kent P. (1972) Optimal Growth the Stock of Resources is Finite and Deplatable. Journal of Economic Theory, v. 4, pp. 256-267.

Andreoni, J., Levinson, A. (1998) The Simple Analytics of the Environmental Kuznets Curve. NBE Working Paper, $\mathrm{n}^{\mathrm{o}} 6793$. 
Arraes, Ronaldo A., Diniz, Marcelo B., Diniz, Márcia J. T. (2006) Curva ambiental de Kuznets e desenvolvimento econômico sustentável, Rio de Janeiro, v. 44, nº 03, p. 525-547.

Arrow, K. et al. (1995) Economic Growth, Carrying Capacity and Environment. Scienci, v. 268, p.520-521.

Azzoni, Carlos R. (1994) Crescimento Econômico e Convergência das Rendas Regionais: o caso Brasileiro à Luz da Nova Teoria do Crescimento. Anais Encontro da ANPEC. p.185-205. Florianópolis-SC.

Azzoni, Carlos R., Carmo, Heron E. Menezes, Tatiane. (2000) Índice de Custo de Vida Comparativo para as Principais Regiões Metropolitanas Brasileiras: 1981-1999. São Paulo: Estudos Econômicos, v.30, n. 1, p.165-186.

Azzoni, Carlos. R. (2003) Economic Growth and Regional Income Inequality in Brazil. The Annals of Regional. Science, 35, pp 133-152.

Barbier, Edward B. (2006) Natural capital, resource dependency and poverty in developing countries: the problem of “dualism with dualism”. In: López, R., Toman, M. A. Economic Development \& Environmental Sustentability, New Options. New York, USA: Oxford University Press.

Barosi-Filho, Milton, Azzoni, Carlos R. (2003) A Time Séries Analysis of Regional Income Convergence in Brazil. Fortaleza: Anais do Fórum Banco do Nordeste de Economia e VIII Encontro Regional de Economia.

Barreto, Flávio A. F. D., Alencar, Frederico A. G., Castelar, Luiz I. M. (2001) Crescimento e Capital Humano: Evidências Empíricas Recentes para o Brasil numa Perspectiva Regional, Capital Humano, Políticas Educacionais e a Trajetória de Crescimento da Economia Brasileira. Fortaleza: Texto para Discussão ${ }^{\circ} 225$, CAEN.

BARRO, Robert J. (1990) Government Spending in a Simple Model of Endogenous Growth. Journal of Political Economy 98(S5): 103-125.

BARRO, Robert J. (2000) Inequality and Growth in a Panel of Countries, Journal of Economic Growth, V.5. $\mathrm{n}^{\circ} 1,87-120$.

BARRO, Robert J., Sala-i-Martin, Xavier, (1992) Convergence, Journal of Political Economy, v. 100, nº 2.

BARRO, Robert J., Sala-i-Martin, Xavier, (1995) Economic Growth, MIT Press.

BAUMOL, William J. (1986) Productivity Growth, Convergence and Welfare, American Economic Review. 76, p.1072-1085.

Becker, Berta K. (2005) Geopolítica da Amazônia. Estudos Avançados, São Paulo, v.19, nº 53.

Bianchi, Marco (1997) Testing for Convergence - Evidence from Non Parametric Multimodality Tests. Journal of Applied Econometrics. 12:4, pp. 393:410.

Brock, William A., Taylor, M. Scott. 2004.

Brundtland, Gro Harlem (org.) (1988) Nosso futuro comum. Relatório da Comissão Mundial sobre Meio Ambiente e Desenvolvimento. Rio de Janeiro: FGV.

Castro, Edna (2005) Dinâmica socioeconômica e desmatamento na Amazônia. Novos Cadernos - NAEA, v.08, n², 5-39, Belém.

Celetano, Daniele, Veríssimo, Adalberto M. (2007) O Avanço da Fronteira na Amazônia: do Boom ao Colapso. IMAZOM, Belém.

Coelho, Rodrigo L. Figueiredo, Lízia de. (2007) Uma Análise da Hipótese da Convergência para os Municípios Brasileiros. Revista Brasileira de Economia, Rio de Janeiro, v.61, nº.3, p.331-351.

Coelho, Rodrigo L. (2006) Uma Análise da Hipótese da Convergência para os Municípios Brasileiros. CEDEPLAR/UFMG. Belo Horizonte.

Cole, M. A., Rayner, A. J., Bates, J. M. (1997) The Environmental Kuznets curve: an empirical analysis. Environmental and Development Economics, v.2, p.401-416.

Dasgupta, P. e Heal, G. (1979) Economic Theory and Exhaustible Resources, Cambridge: Cambridge University Press. 
Dasgupta, P., Heal, G.M. (1974) The Optimal Depletion of Exhaustible Resources. Review of Economic Studies (Symposium, 1974), pp.3-28.

DE LONG, Bradford (1988) Productiviy Growth, Convergence and Welfare: Comment, American Economic Review, December, 78, pp. 1138-1154.

Diniz, Márcia J. T. (2008) A dinâmica das inovações nas empresas do pólo industrial de Manaus: um novo momento relacionado aos constrangimentos ambientais a partir do ano 2000. NAEA, Belém.

Diniz, Márcia J. T. Diniz, Marcelo B. (2005) Trajetórias da Qualidade Ambiental e do Desenvolvimento Econômico Sustentável. Belém. UFPA.

Durlauf, Steven N., Johnson, Paul A. (1995) Multiple Regimes and cross-country growth behavior. Journal of Applied Econometrics, v.10, p.365-384.

Enriquez, Maria A. R. S. (2007) Maldição ou Dádiva? Os dilemas do Desenvolvimento Sustentável a partir de uma Base Mineira. Brasília: CDS/UNB.

Fearnside, Philip M. Desmatamento na Amazônia: dinâmica, impactos e controle. Instituto Nacional de Pesquisas da Amazônia - INPA, v. 36(3) 2006: 395 - 400

Ferreira, Afonso Henrique B. (1998) Convergence in Brazil Past and Future. Belo Horizonte: Centro de Desenvolvimento e Planejamento Regional - CEDEPLAR, Faculdade de Ciências Econômicas FACE, Universidade Federal de Minas Gerais - UFMG. Texto para Discussão no 119.

FERREIRA, Afonso Henrique Borges (1999) Concentração Regional e Dispersão das Rendas per capita Estaduais: um comentário, Estudos Econômicos, v. 29, n. 1, p. 47-63.

FERREIRA, Afonso, Diniz, Clélio (1995) Convergência entre as rendas per capita estaduais no Brasil, Revista de Economia Política, v. 15, n. 4, (60).

Ferreira, Leandro V., Venticinque Eduardo, Almeida, Samuel (2005) O desmatamento na Amazônia e a importância das áreas protegidas, Estudos Avançados, 54, p.157-166.

Fonseca, L., Ribeiro, E., (2005) Preservação ambiental e crescimento econômico no Brasil. In: ENCONTRO DE ECONOMIA DA REGIÃO SUL, VII, 2005. Preservação ambiental e crescimento econômico no Brasil. Rio Grande do Sul.

Friedman, Milton. (1992) Do Old Fallacies Ever Dies? Journal of Economic Literature, v. 30, p.2129-2132.

Gondim, Luis B., Barreto, Flávio A., Carvalho, José Raimundo (2007) Condicionantes de Clubes de Clubes de Convergência no Brasil. Rio de Janeiro. Estudos Econômicos, v. 37. n.1. p. 71-100.

Grossman, G. M., Krueger, A. B. (1995) Economic Growth and Environment. The Quarterly Journal of Economics. May, p. 353-377.

Gylfason, T., Hebertsson, T. T., Zoega, G. (1999) A Mixed Blessing: natural resources and economic growth. Macroeconomics Dynamics 3, p. 204-205.

Gylfason, Thorvaldur (2001) Natural Resources, Education, and Economic Development. European Economic Review 45, P. 847-859.

Hamilton, K. (1995) Sustainable Development, the Hartwick Rule and Optimal Growth. Environmental and Resource Economics 5, 393-411.

Hamilton, Kirk e Hassan, Rashid (2006) Measuring Development Prospects by 'Greening' the National Accounts. In: Economic Development \& Enviromental Sustainability. Oxford, 61-89.

Harbaugh, W., Levinson, A. Wilson, D. (2000) Reexaming The Empirical Evidence for an Environmental Kuznets Curve. NBE Working Paper 7711.

Hilton, F. G. H., Levinson, A. (1998) A Factoring the Environmental Kuznets Curve: evidence from automotive lead emissions. Journal of Environmental Economics and Management, v. 35, p.126-141.

Johnson, P., Takeyama, L. (2003) Convergence among the US States: absolute, conditional or club? Poughkeepsie: Department of Economics Vassar College, Working Paper Series, 50.

Kamien, Morton I., Schwartz, Nancy L. (1978) Optimal Exhaustible Resource Depletion with Endogenous Technical Change. Review of Economic Studies, v. 45, pp.179-196. 
Laurini, Márcio, Andrade, Eduardo, Pereira, Pedro L. V. (2003) Clubes de Convergência de Renda para os Municípios Brasileiros: Uma Análise Não-Paramétrica. São Paulo. Ibmec Working Paper.

LUCAS, Robert E. (1988) On the Mechanics of Economic Development, Journal of Monetary Economics, 22, p. 3-42.

Magalhães,André M. (2001)Clubes de convergência no Brasil: uma abordagem com correção espacial.UFPE.

Mankiw, Gregory, Romer, David, Weil, David (1992) Contribution to the Empirics of Economic Growth. The Quarterly Journal of Economics, p.407-37.

Margulis, Sergio (2003) Causas do Desmatamento da Amazônia Brasileira BANCO MUNDIAL Brasil.

Mossi, Mariano, Aroca, Patrício, Fernandez, Ismael, Azzoni, Carlos (2001) Growth Dynamics and Space in Brazil. European Regional Science Association.

Mueller, Charles C. (2007) Os economistas e as relações entre o sistema econômico e o meio ambiente. Brasília: FINATEC, UNB.

Oliveira Júnior, José N., Castelar, Ivan e Ferreira, Roberto T. (2007) Convergência Microrregional no Setor Agrícola usando um Modelo Threshold. Recife: Anais do XXXVI Encontro Nacional de Economia - ANPEC.

Oliveira, Lívio L. S., Porto Júnior, Sabino S. (2004) O Desenvolvimento Sustentável e a Contribuição dos Recursos Naturais para o Crescimento Econômico: Uma Aplicação para o Brasil.

Paixão, Alex S. (2008) Estudo sobe Convergência de Renda entre os Municípios da Amazônia Legal no Período de 1980 a 2004. Belém: UFPA. Monografia.

PORTO Jr., Sabino, Souza, Nali J. (2002) Crescimento Regional e novos testes de convergência para os municípios da Região Nordeste do Brasil. Programa de Pós-Graduação em Economia - UFRGS, Texto para Discussão $n^{\circ}$ 2002/11.

PRITCHETT, Lant, (1997) Divergence, Big Time, Journal of Economic Perspectives, v. 11. n. 3. Summer. p. 3-17.

Quah, Danny (2000) The tsrf Reference Manual, LSE Economics Department, July.

Quah, Danny (1993) Empirical Cross-Section Dynamics in Economic Growth, LSE Working Paper.

Quah, Danny (1997) Empirics for Growth and Distribution: Stratification, Polarization, and convergence Clubs, Journal of Economic Growth, 2, p. 27-59.

Rivero, S., Almeida, O., Ávila. S., Oliveira. W. (2009) Pecuária e Desmatamento: Uma Análise das Principais Causas Diretas do Desmatamento na Amazônia. Nova Economia nº 19 (1) 41 - 66.

Romer, David, Mankiw, Gregory, Weil, David (1992) A Contribution to the Empirics of Economic Growth. Quarterly Journal of Economics. p. 407-37.

Sachs, Jeffrey D., Warner, Andrew M. (2001) Natural Resources and Economic Development The curse of natural resources, European Economic Review, v.45, p. 827-838.

Sachs, Jeffrey D., Warner, Andrew M. (1995) Natural Resource Abundance and Economic Growth, Cambridge, NBER, Working Paper 5398, dec.

SALA-I-MARTIN, Xavier (1996) The classical approach to convergence analysis. The Economic Journal, 106.p. 1019-1036.

Schneider, R., Arima, E., Veríssimo, A., Barreto, P., Souza Jr., C. (2000) Amazônia Sustentável: limitantes e oportunidades para o desenvolvimento rural. Imazon \& Banco Mundial. Série Parcerias, $\mathrm{n}^{\circ}$ 01. Belém, Brasília, 57 p.

Schwartsman, Alexandre (1996) Convergence across Brazilian states. IPE/USP, Texto para Discussão, n.2.

Selden, T. M., Song, D. (1994) Environmental Quality and Development: is there a Kuznets Curve for air Pollution Emission? Journal of Environmental Economics Management, v. 27, p.147-162.

Shafik, N. (1994) Economic Development and Environmental Quality: An Econometric Analysis. Oxford Economic Papers. n.46. 
Silva, Sandra, Silva, Mário R. (2000) Crescimento Econômico nas Regiões Européias: Uma avaliação sobre a persistência das disparidades regionais no período 1980-95. CEDRES, Faculdade de Economia do Porto, Roberto Frias.

SILVERMAN, Bernard (1986) Density Estimation for Statistics and Data Analysis, Chapman \& Hall/CRC.

Soares Filho, Britaldo S., Nepstad, Daniel C., Curran. Lisa, Cerqueira, Gustavo C., Garcia, Ricardo A., Ramos, Claudia A., Voll, Eliane, Macdonald, Alice, Lefebvre, Paul, Schlesinger, Peter, Macgrath, David (2005) Cenários de Desmatamento para a Amazônia, Estudos Avançados, 54, p.137-152.

Solow. Robert (1993) An almost practical step toward sustainability. Resource Policy, UK, Elsevier, v. 19, n.3. p. 167-172.

Stiglitz, Joseph. (1974) Growth with Exhaustible Natural Resources: Efficient and Optimal Growth Paths. The Review of Economic Studies, v. 41, Symposium on the Economics of Exhaustible Resources, pp. 123-137.

Stokey, N. Are There Limits to Growth? International Economic Review, 39, 1-31.

Vergolino, José R., Gomes, Gustavo M. (1997) Trinta e Cinco Anos de Crescimento Econômico na Amazônia (1960/1995). Brasília. IPEA.

Zini Jr., Álvaro. (1998) Regional Income Convergence in Brasil and it's socio-economic determinants, Economia Aplicada, v. 2. 